\title{
The importance of health behaviours in childhood for the development of internalizing disorders during adolescence
}

\author{
Xiu Yun Wu ${ }^{1,3}$, Sara F. L. Kirk ${ }^{1,2}$, Arto Ohinmaa ${ }^{3^{*}}$ (D) and Paul J. Veugelers ${ }^{3}$
}

\begin{abstract}
Background: Poor mental health constitutes a considerable global public health burden with approximately half of all cases of poor mental health having their onset before the age of 14 years. The identification of modifiable risk factors early in life is therefore essential to prevention, however, there are presently very few longitudinal studies on health behaviours for mental health to inform public health decision makers and to justify preventive action. We examined the importance of diet quality, physical activity (PA) and sedentary behaviours in childhood for internalizing disorder throughout adolescence.

Methods: We linked data from a population-based lifestyle survey among 10 and 11 year old grade five students in the Canadian province of Nova Scotia with physician diagnoses of internalizing disorders from administrative health records. We applied negative binomial regressions to examine the associations of health behaviours with the number of health care provider contacts with a diagnosis of internalizing disorder.

Results: Of the 4875 students, $23.9 \%$ had one or more diagnoses for internalizing disorder between the age of 10 or 11 years and 18 years. The number of health care provider contacts with a diagnosis of internalizing disorder was statistically significant higher among students with less variety in their diets, and among students who reported less PA and more time using computers and video games. The number of health care provider contacts was also higher for girls, and for students with low self-esteem and from low-income households.

Conclusions: These findings suggest that diets and active lifestyles in childhood affect mental health during adolescence, and imply that succxessful health promotion programs targeting children's diets and activity will contribute to the prevention of mental health disorders in addition to the prevention of chronic diseases later in life.
\end{abstract}

Keywords: Children, Adolescents, Diet quality, Physical activity, Sedentary behaviour, Internalizing disorders, Health behaviours

\section{Background}

Poor mental health constitutes a considerable global public health burden with approximately one in four people experiencing one or more episodes of poor mental health throughout their lifetime [1, 2]. Approximately half of all cases of poor mental health have their onset before the age of 14 years [3]. Individuals experiencing poor mental health in childhood and adolescence are more likely to develop more severe forms of mental

\footnotetext{
* Correspondence: aohinmaa@ualberta.ca

${ }^{3}$ School of Public Health, University of Alberta, Edmonton, AB T6G 1C9, Canada

Full list of author information is available at the end of the article
}

health challenges and to engage in risky behaviours like substance use, or attempt suicide in adulthood $[4,5]$.

Various cross-sectional studies among children and adolescents have reported associations of diet [6,7], physical activity (PA) [8-12] and sedentary behaviour (SB) [13-16] and mental health status, characterized as internalizing disorders (including depression, anxiety, distress, mood disorder). However, there are few longitudinal studies that have examined the importance of these health behaviours in childhood for mental health later in life [17-25], and those that exist have produced incomplete or inconsistent findings. We have identified only two prospective studies that reported a significant relationship 
between low diet quality and poor mental health in adolescents $[17,18]$, whereas others reported little or no relationship [19]. While several prospective studies have indicated positive effects of physical activity on future mental health in adolescents and young adulthood [20-23], other studies have not found such an effect [24-26]. Relative to childhood PA for mental health, the association of sedentary behaviour with mental health among children and youth has been less investigated [13] and the evidence of sedentary behaviour as a risk factor for development of poor mental health in youth is scarce [13, 14]. Some crosssectional studies have demonstrated an adverse effect of sedentary behaviour on mental health in children and adolescents $[9,10,15,16]$. Nevertheless, populationbased longitudinal studies among youth are lacking for the effect of sedentary behaviour on the mental health problem of internalizing disorders, in which the potential confounding influence of socioeconomic factors as well as other health behaviours (e.g., PA, diet quality) is considered. The limitations of existing studies on the aforementioned health behaviours for mental health include use of crosssectional designs, few prospective studies with limited follow up, or not accounting for other important indicators and diverse socioeconomic confounders [6, 8, 13]. For example, most of the prior studies on health behaviours and mental health in youth have examined a single or two behaviours (e.g., diet or PA or sedentary behaviours), rather than considering multiple health behaviours and socioeconomic confounders simultaneously [9-11, 13]. In addition, very few studies have included indicators of specific aspects of self-esteem in childhood for future mental health in adolescence [27]. Moreover, most studies have relied on self-reported measures of mental health disorders rather than on a physician diagnosis as a manifestation of objective and clinically significant mental health issues. More longitudinal studies are needed to better understand influences of diet quality, PA and sedentary behaviours on mental health disorders.

Previously we reported that diet quality, in terms of more variety of food items in the diet, was associated with a lower risk of physician diagnosed internalizing disorders among a population-based sample of children over three years of follow up [19]. The present study extends this work by examining several health behaviours, diet quality, PA and sedentary behaviours, as well as self-esteem in relation to physician diagnosed internalizing disorders during 8 years of follow up, with the aim to better inform public health decision makers on intervention programs to improve mental health outcomes among children and youth. Based on established literature we identified diet quality, PA and sedentary behaviour as potentially relevant health behaviours, and sociodemographics as potential confounders $[7,8,13,17,24,27]$. The purpose of the study was to investigate the effect of these health behaviours in childhood on the number of health care provider contacts with a primary diagnosis of internalizing disorders in adolescence. The number of health care provider contacts with a primary diagnosis of internalizing disorders given by a physician or a medical specialist was derived from administrative health data in the province of Nova Scotia. Administrative health data has been widely used in mental health epidemiologic and health services research, and has been demonstrated feasible and valid in identifying a mental disorder $[28,29]$.

\section{Methods}

This examination of the relationship between health behaviours and internalizing disorders used behavioural information taken from a survey, the 2003 Children's Lifestyle and School Performance Study (CLASS) [30], linked with physician diagnoses obtained from administrative health records.

\section{The survey}

The CLASS study was a population-based survey among grade five students, who were primarily 10 and 11 years old at the time of survey administration, and their parents in the province of Nova Scotia, Canada. The study examined the importance of health behaviours and academic performance. Of all 291 provincial public schools with grade five students, 282 schools participated in the study. The average participation rate was $51.1 \%$ per school. Of the 5517 grade five students who received parental consent to participate in the study, 5200 students completed the surveys [30].

The CLASS study consisted of a home survey that was completed by parents, a student survey with questions on PA, sedentary activities and self-esteem, and a Canadianized version of the Harvard Youth/Adolescent Food Frequency Questionnaire (YAQ) [31] administered in the schools by study assistants. Study assistants also measured standing height of the students to the nearest $0.1 \mathrm{~cm}$ and body weight to the nearest $0.1 \mathrm{~kg}$ on calibrated digital scales. The home survey collected information on children' place of residency, gender, household income, and highest level of parental education. In addition, participating parents provided the Nova Scotia health insurance number for their child and consent to allow for future data linkage with administrative health databases.

\section{Administrative health data}

The administrative health data were derived from the Medical Services Insurance (MSI) database and the Canadian Institute for Health Information Discharge Abstract Database (CIHI DAD). The MSI database is administered by Medavie Blue Cross for the province of Nova Scotia and contains records for each insured health service rendered by a physician (including emergency 
room visits) and paid for by the Nova Scotia provincial health care system. The CIHI DAD contains a comprehensive administrative transcription of each admission to a Nova Scotia hospital facility. Both of these databases contain individual patient-level information including patient demographic characteristics, visiting physicians, diagnoses and procedures received, service transfers while in hospital, and specialty services received. Data were available from 1992 (when the grade five students who participated in 2003 were born) to 2011 (when participating students turned 18 years of age).

Of the 5200 students who completed the survey, 4875 (94\%) provided valid health card numbers and were successfully linked with the administrative health data.

\section{Health behaviours}

The exposures of interest were diet quality, PA and sedentary behaviours. On the basis of students' nutrient intake and dietary information from the YAQ [31] and Canadian Nutrient Files [32], we calculated intake of nutrients and daily energy intake, number of daily servings of fruits and vegetables. We then calculated the Diet Quality Index (DQI) based on the composite measure, DQI-international (DQI-I) [33]. The DQI-I scores ranges between 0 and 100, with higher scores indicating a better diet quality. The DQI-I constitutes four components: variety, adequacy, moderation and overall balance of the diet. DQI-I variety evaluates the extent to which food intake comes from diverse sources within and between food groups. DQI-I adequacy examines whether the intake of foods is adequate to meet the requirement for a healthy diet. DQI-I moderation assesses intakes of foods and nutrients (i.e. fat intake) that need restriction due to their associations with chronic diseases. DQI-I balance examines the proportion of intakes from different energy sources. The DQI-I balance was categorized into two groups: 'poor' and 'good' balance. All other diet quality indicators were divided into tertiles, with higher tertiles indicating better diet quality.

The CLASS survey included questions from the National Longitudinal Survey for Children and Youth [34] on playing sports or physical activities with and without a coach. The question was reported as weekly engagement in the physical activities: Never, 1 to 3 times/ week, $\geq 4$ times/week. Sedentary behaviour was captured through questions on daily number of hours spent on playing computers or video games, and on watching television, with less than $1 \mathrm{~h} /$ day, $1-2 \mathrm{~h} /$ day, $2-4 \mathrm{~h} /$ day, and $\geq 5 \mathrm{~h} /$ day as response categories.

\section{Internalizing disorders}

Participants were considered to have a mental disorder if they received one or more diagnoses of internalizing disorders according to the International Classification of
Diseases, Ninth Revision, Clinical Modification (ICD-9CM) or Tenth Revision, (ICD-10-CA). The ICD-9 and ICD-10 codes for internalizing disorders in this study are shown in Table 1. All diagnoses of internalizing disorders between 2003 when children were 10 to 11 years and 2011 when the participants turned 18 years were considered.

\section{Confounders}

We considered gender, household income, parental educational attainment, residential location, body weight status, and self-esteem as potential confounders in the relationship between health behaviours and internalizing disorders. We considered household income at 4 levels: $\$ 0$ to $\$ 20,000 ; \$ 20,001-\$ 40,000 ; \$ 40,001-\$ 60,000 ;>\$ 60,000$, parental education attainment as secondary school or less; college, and university or above. Residential location was classified as urban and rural area. We applied the ageand gender-specific body mass index cut-off points for children established by the International Obesity Task Force [35] to categorize body weights as normal weight, overweight and obesity. Total energy intake was also adjusted for as per established recommendations for analysing food frequency data [36].

The CLASS survey included 11 questions related to self-esteem. Response options for each were 'Never or almost Never', 'Sometimes' and 'Often or almost Always' [37]. By means of principal component analysis (PCA), we reduced the 11 questions to four components: selfperception, externalizing problems, internalizing problems and social-perception [38]. The predicted self-esteem scores for each of these four components were considered as confounders as self-esteem is strongly associated with mental health and potentially associated with health behaviours [27, 38].

\section{Statistical analysis}

Descriptive analysis was used to present the frequency distribution of socio-demographic characteristics and health behaviours of children and the percentage with internalizing disorders in adolescence. The Chi-square test was applied to assess differences in weighted estimates for internalizing disorders between groups by socio-demographic and health behaviours. To examine the association of diet quality, PA, sedentary behaviour with internalizing disorders, we applied

Table 1 ICD-9 and ICD-10 codes identifying diagnosis of internalizing disorder

\begin{tabular}{lll}
\hline Internalizing disorder & ICD-9 code & ICD-10 code \\
\hline Depressive episode, recurrent depressive & $296,296.2$, & F32, F33, F34, \\
disorder, recurrent/persistent or unspecified & $296.3,296.9$, & F38, F39, F40, \\
mood disorder (excluding bipolar), & $300,308,309$, & F41, F42, F43, \\
$\begin{array}{l}\text { neurotic disorder, general anxiety } \\
\text { disorder, reaction to stress, adjustment }\end{array}$ & 311,313 & F48, F92, F93 \\
reaction, emotional disorders & \\
\hline
\end{tabular}


univariable and multivariable negative binomial regression models (NBM) using the number of health care provider contacts for internalizing disorders as the outcome. NBM is preferred over Poisson regressions when the outcome data is over-dispersed [39] which was the case in the present study. The multivariable NBM was adjusted for the confounding influence of students' gender, residential location, household income, parental education, body weight status, energy intake and self-esteem. We also performed univariable and multivariable logistic regressions to examine the effect of the health behaviours on the diagnosis of internalizing disorders, where a binary outcome variable was used indicating whether the students received a diagnosis of an internalizing disorder during the follow up. Missing values for household income (23.2\%), parental education (7.2\%) and body weight status $(20.2 \%)$ were considered as separate covariate categories in the regression models, and the estimates for these categories were not presented. As response rates in residential areas with lower household income were slightly lower than the average, we weighted the analyses using response weights such that the estimates represent the population of grade five students in the province of Nova Scotia [40]. The statistical tests for significance were set at $p<0.05$. We used the statistical software of STATA 13.1 (Stata Corp., College Station, TX, USA) for the statistical analysis.

\section{Results}

Over the course of approximately eight years when students matured from age 10 or 11 to age 18 years, 1164 (23.9\%) had one or more health care provider contacts with a diagnosis of internalizing disorder following the CLASS survey (Table 2). Girls had a higher proportion (28.1\%) of health care provider contacts for internalizing disorders than boys (19.9\%). The proportion of students with a diagnosis of internalizing disorders was higher among students who reported lower PA levels and students from low income households, and students attending schools in urban areas.

Of the 1164 students who had one or more health care encounters for internalizing disorders, 52.3\%, 19.3\%, 9.6\% and $18.8 \%$ of them had one, two, three and four or more service encounters, respectively between age 10 or 11 and age 18 years. Table 3 presents the univariable and multivariable adjusted incidence rate ratios (IRR) and 95\% confidence intervals (CIs) for the association between health behaviours and number of health care encounters with diagnosis of internalizing disorders. The multivariable analyses presented under Model 1 are adjusted for the confounding potential of characteristics listed in Table 3 with the exception of self-esteem, and those under Model 2 are adjusted for all characteristics in the table including self-esteem. Diet variety, physical activity without a coach, use of computers and playing video games were found to be associated with the number of service encounters for
Table 2 Socio-demographic characteristics and percentage (\%) with an internalizing disorder among participants of the Children's Lifestyle and School Performance Study, Nova Scotia, Canada

\begin{tabular}{lll}
\hline Variable & Percentage & $\begin{array}{l}\text { Percentage with } \\
\text { internalizing disorder }\end{array}$ \\
\hline Physical activity without coach & & $P=0.103$ \\
$\quad$ Never & 9.2 & 28.1 \\
1 to 3 times/week & 34.0 & 23.7 \\
$\geq 4$ times /week & 56.8 & 23.4 \\
Physical activity with coach & & $P=0.003$ \\
$\quad$ Never & 37.5 & 26.5 \\
1 to 3 times/week & 44.8 & 23.0 \\
$\geq 4$ times /week & 17.8 & 20.8 \\
Use of computers or playing video & & $P=0.079$
\end{tabular}
games

\begin{tabular}{|c|c|c|}
\hline Less than $1 \mathrm{~h} /$ day & 42.7 & 22.1 \\
\hline $1-2$ h/day & 38.7 & 25.5 \\
\hline 3-4 h/day & 12.3 & 25.4 \\
\hline$\geq 5$ h/day & 6.3 & 23.1 \\
\hline Watching TV & & $P=0.449$ \\
\hline Less than $1 \mathrm{~h} /$ day & 14.6 & 25.8 \\
\hline $1-2$ h/day & 40.2 & 22.6 \\
\hline 3-4 h/day & 29.2 & 24.7 \\
\hline$\geq 5$ h/day & 16.0 & 24.5 \\
\hline Body weight status & & $P=0.635$ \\
\hline Normal weight & 67.2 & 24.9 \\
\hline Overweight & 23.0 & 24.4 \\
\hline Obese & 9.8 & 22.6 \\
\hline Household income & & $P<0.001$ \\
\hline$<\$ 20,000$ & 11.9 & 33.7 \\
\hline$\$ 20,001-\$ 40,000$ & 22.6 & 26.2 \\
\hline$\$ 40,001-\$ 60,000$ & 26.4 & 24.2 \\
\hline$>\$ 60,000$ & 39.1 & 19.9 \\
\hline Parental education & & $P=0.027$ \\
\hline Secondary school or less & 30.5 & 26.2 \\
\hline College & 37.6 & 23.9 \\
\hline University or above & 31.9 & 21.8 \\
\hline Residence & & $P=0.004$ \\
\hline Rural & 32.7 & 21.5 \\
\hline Urban & 67.3 & 25.3 \\
\hline Gender & & $P<0.001$ \\
\hline Boys & 49.2 & 19.9 \\
\hline Girls & 50.8 & 28.1 \\
\hline
\end{tabular}

All estimates were weighted to represent estimates for grade five students in Nova Scotia. The Chi-square test was used to obtain the $P$-values in the table

internalizing disorders in a statistical significant manner. Relative to children in the lowest tertile, children in the middle tertile for diet variety had $25 \%$ lower health care 
provider visits with a diagnosis of internalizing disorders (Table 3, Model 1). Children who played sports or undertook PA without a coach 1 to 3 times a week had a lower rate (IRR $=0.69,95 \% \mathrm{CI}$ : $0.51,0.93$ ) of receiving health care for internalizing disorders than children who never played sports or undertook PA without a coach. More time spent on using computers or playing video games was associated with a higher number of health care provider contacts for a diagnosis of internalizing disorders. These risk estimates remained largely the same when further adjusted for self-esteem (Table 3, Model 2). Children reporting poor self-esteem for the internalizing sub-scale (IRR $=1.26$, 95\% CI: $1.05,1.51)$ and for the social-perception subscale (IRR $=1.39,95 \%$ CI: $1.15,1.69)$ were more likely to receive health care related to internalizing disorders. The association between body weight status and the diagnosis for internalizing disorders (Table 2) and the number of visits receiving health services for internalizing disorders (Table 3 ) was not statistically significant $(P>0.05)$.

The risk estimates for diagnoses of internalizing disorders after adjustment for diagnoses of internalizing disorders prior to the survey in 2003 were similar to those presented in Table 3. In addition, logistic regression analyses providing risk estimates for health behaviours with respect to the first diagnosis of internalizing disorders were similar, though less pronounced, as those presented in Table 3. The results of the logistic regression analyses are included in the Additional file 1: Table S1.

\section{Discussion}

This study reveals that low dietary variety, physical inactivity and sedentary behaviour, as measured by increased time spent on use of computers and playing video games in childhood, were associated with a greater number of health care encounters with diagnoses of internalizing disorders during adolescence. As these associations are independent of socio-demographic factors, body weight and self-esteem in childhood, they suggest these health behaviours are associated with the development of internalizing disorders during adolescence.

We observed that children with diets comprising a good variety of food items were less likely to develop internalizing disorders throughout adolescence, consistent with our earlier work showing this for a three-year period of follow up [19]. Other research has shown that adults who consume a greater variety of foods are also more likely to consume nutrient-dense foods to achieve a balanced diet [41]. Exposing children and youth to a wide variety of food sources may therefore help them meet their nutritional needs, thereby reducing the likelihood of developing internalizing disorders. While a prospective study in Australian adolescents aged 11-18 years reported an association between poor diet quality and mental health problems during 2-years of follow-up [17], our observations suggest that inadequate dietary variety may be the more salient aspect of diet quality that contributes to the development of internalizing disorders.

Benefits of physical activity for mental health among children and adolescents have been well documented in cross-sectional studies [8]. The existing longitudinal studies on the effect of physical activity on mental health in adolescents and young adults have been less consistent [20-26, 42, 43]. A longitudinal study among German adolescents and young adults reported that physical activity was associated with a lower incidence of mental disorders over a 4-year follow-up [42]. For US adolescents followed for 2 years, Motl et al. reported that a change in frequency of physical activity was related to an inverse change in depressive symptoms [43]. A more recent study examining the association between leisure time PA in adolescents and mental health in early adulthood, found that a low level of leisure time PA in adolescent girls was related to poor mental health at 20/21 years old [20]. The above findings are consistent with our observation that lower rates of physical activity without a coach are associated with the development of internalizing disorders over a period of eight years. We also observed that lower rates of physical activity with a coach was associated with internalizing disorders but this association appeared not to be statistically significant when confounders were considered (Table 3). In contrast, several other prospective studies observed no association between physical activity and later depressive symptoms [24-26, 44].

We had examined the effect of two different indicators of sedentary behaviour on internalizing disorders, one being the use of computers or playing video games, and the other watching TV. Our observation that children who used computers and video games more frequently were more likely to develop internalizing disorders seems consistent with studies reporting that playing computers and video games is related to an elevated risk of mental health problems among children and adolescents such as depression, anxiety, and emotional problems [15, 45, 46]. Our observation that TV watching was not associated with internalizing disorders is also consistent with findings from some studies $[15,45,47]$, though other studies did report an association with depression, one of the common internalizing disorders [48, 49]. Differences across studies may arise from different assessment methods, differences in mental health definitions, differences in duration of follow up, and whether other health behaviours were considered in the statistical analyses. The present study contributes to the literature by demonstrating a prospective association of use of computers and video games with internalizing disorders during adolescence, independent of physical activity levels, diet quality, socio-demographic characteristics and self-esteem. This is in agreement with a 
Table 3 Associations of health behaviours in childhood with number of health care provider contacts with a primary diagnosis of an internalizing disorder in adolescence among participants of the Children's Lifestyle and School Performance Study, Nova Scotia, Canada

\begin{tabular}{|c|c|c|c|}
\hline Variable & $\begin{array}{l}\text { Univariable Model } \\
\text { IRR }(95 \% \mathrm{Cl})\end{array}$ & $\begin{array}{l}\text { Multivariable Model } 1 \\
\text { IRR }(95 \% \text { Cl) }\end{array}$ & $\begin{array}{l}\text { Multivariable Model } 2 \\
\text { IRR }(95 \% \mathrm{Cl})\end{array}$ \\
\hline \multicolumn{4}{|l|}{ DQI-I variety } \\
\hline Lowest tertile & 1.0 & 1.0 & 1.0 \\
\hline Middle tertile & $0.81(0.66,1.01)$ & $0.75(0.58,0.98)$ & $0.77(0.60,0.99)$ \\
\hline Highest tertile & $0.93(0.72,1.20)$ & $0.84(0.60,1.19)$ & $0.84(0.59,1.18)$ \\
\hline \multicolumn{4}{|l|}{ DQI-I moderation } \\
\hline Lowest tertile & 1.0 & 1.0 & 1.0 \\
\hline Middle tertile & $1.02(0.82,1.28)$ & $0.98(0.72,1.32)$ & $0.97(0.71,1.34)$ \\
\hline Highest tertile & $1.15(0.89,1.48)$ & $1.10(0.77,1.57)$ & $1.10(0.76,1.58)$ \\
\hline \multicolumn{4}{|l|}{ DQI-I adequacy } \\
\hline Lowest tertile & 1.0 & 1.0 & 1.0 \\
\hline Middle tertile & $1.04(0.82,1.31)$ & $1.22(0.90,1.65)$ & $1.31(0.95,1.80)$ \\
\hline Highest tertile & $1.04(0.81,1.33)$ & $1.19(0.79,1.78)$ & $1.26(0.83,1.91)$ \\
\hline \multicolumn{4}{|l|}{ DQI-I balance } \\
\hline Poor balance $($ score $<1)$ & 1.0 & 1.0 & 1.0 \\
\hline Good balance (score $\geq 1$ ) & $1.04(0.86,1.27)$ & $0.94(0.76,1.17)$ & $0.91(0.73,1.13)$ \\
\hline \multicolumn{4}{|l|}{ DQI-I overall } \\
\hline Lowest tertile & 1.0 & 1.0 & 1.0 \\
\hline Middle tertile & $0.89(0.70,1.14)$ & $0.92(0.73,1.17)$ & $0.97(0.77,1.23)$ \\
\hline Highest tertile & $1.02(0.81,1.29)$ & $1.17(0.79,1.73)$ & $1.21(0.83,1.76)$ \\
\hline \multicolumn{4}{|l|}{ Physical activity without coach } \\
\hline Never & 1.0 & 1.0 & 1.0 \\
\hline 1 to 3 times/week & $0.71(0.51,1.00)$ & $0.69(0.51,0.93)$ & $0.70(0.51,0.96)$ \\
\hline$\geq 4$ times/week & $0.78(0.56,1.07)$ & $0.81(0.60,1.09)$ & $0.83(0.61,1.13)$ \\
\hline \multicolumn{4}{|l|}{ Physical activity with coach } \\
\hline Never & 1.0 & 1.0 & 1.0 \\
\hline 1 to 3 times/week & $0.79(0.64,0.98)$ & $0.87(0.71,1.07)$ & $0.87(0.71,1.07)$ \\
\hline$\geq 4$ times /week & $0.62(0.46,0.85)$ & $0.76(0.57,1.02)$ & $0.79(0.58,1.07)$ \\
\hline \multicolumn{4}{|c|}{ Use of computers or playing video games } \\
\hline Less than $1 \mathrm{~h} /$ day & 1.0 & 1.0 & 1.0 \\
\hline 1-2 h/day & $1.40(1.12,1.74)$ & $1.57(1.27,1.93)$ & $1.56(1.26,1.93)$ \\
\hline 3-4 h/day & $1.15(0.87,1.52)$ & $1.49(1.12,1.98)$ & $1.42(1.06,1.91)$ \\
\hline$\geq 5$ h/day & $1.18(0.83,1.68)$ & $1.78(1.19,2.67)$ & $1.67(1.10,2.54)$ \\
\hline \multicolumn{4}{|l|}{ Watching TV } \\
\hline Less than $1 \mathrm{~h} /$ day & 1.0 & 1.0 & 1.0 \\
\hline 1-2 h/day & $0.97(0.74,1.27)$ & $0.97(0.74,1.27)$ & $0.98(0.74,1.29)$ \\
\hline 3-4 h/day & $1.04(0.79,1.36)$ & $0.93(0.71,1.22)$ & $0.93(0.71,1.23)$ \\
\hline$\geq 5$ h/day & $0.85(0.65,1.12)$ & $0.79(0.58,1.07)$ & $0.77(0.56,1.06)$ \\
\hline \multicolumn{4}{|l|}{ Body weight status } \\
\hline Normal weight & 1.0 & 1.0 & 1.0 \\
\hline Overweight & $1.08(0.81,1.44)$ & $1.07(0.84,1.36)$ & $1.05(0.83,1.32)$ \\
\hline Obese & $1.13(0.73,1.75)$ & $0.93(0.68,1.28)$ & $0.85(0.62,1.18)$ \\
\hline
\end{tabular}


Table 3 Associations of health behaviours in childhood with number of health care provider contacts with a primary diagnosis of an internalizing disorder in adolescence among participants of the Children's Lifestyle and School Performance Study, Nova Scotia, Canada (Continued)

\begin{tabular}{|c|c|c|c|}
\hline Variable & $\begin{array}{l}\text { Univariable Model } \\
\text { IRR (95\% Cl) }\end{array}$ & $\begin{array}{l}\text { Multivariable Model } 1 \\
\text { IRR }(95 \% \text { CI) }\end{array}$ & $\begin{array}{l}\text { Multivariable Model } 2 \\
\text { IRR }(95 \% \text { Cl) }\end{array}$ \\
\hline \multicolumn{4}{|l|}{ Gender } \\
\hline Boys & 1.0 & 1.0 & 1.0 \\
\hline Girls & $1.62(1.32,1.98)$ & $1.64(1.36,1.98)$ & $1.61(1.33,1.96)$ \\
\hline \multicolumn{4}{|l|}{ Household income } \\
\hline$<\$ 20,000$ & 1.0 & 1.0 & 1.0 \\
\hline$\$ 20,001-\$ 40,000$ & $0.74(0.54,1.01)$ & $0.76(0.57,1.02)$ & $0.82(0.61,1.11)$ \\
\hline$\$ 40,001-\$ 60,000$ & $0.81(0.57,1.15)$ & $0.81(0.60,1.09)$ & $0.84(0.62,1.14)$ \\
\hline$>\$ 60,000$ & $0.57(0.41,0.78)$ & $0.54(0.40,0.73)$ & $0.59(0.43,0.79)$ \\
\hline \multicolumn{4}{|l|}{ Parental education } \\
\hline Secondary school or less & 1.0 & 1.0 & 1.0 \\
\hline College & $0.80(0.63,1.02)$ & $0.87(0.70,1.08)$ & $0.84(0.68,1.05)$ \\
\hline University or above & $0.81(0.63,1.05)$ & $0.94(0.73,1.20)$ & $0.98(0.76,1.27)$ \\
\hline \multicolumn{4}{|l|}{ Residence } \\
\hline Rural & 1.0 & 1.0 & 1.0 \\
\hline Urban & $1.44(1.17,1.76)$ & $1.65(1.37,1.99)$ & $1.73(1.43,2.1)$ \\
\hline \multicolumn{4}{|c|}{ Self-esteem (Low vs. high self-esteem) } \\
\hline Self-perception & $1.24(1.01,1.52)$ & & $1.19(0.98,1.43)$ \\
\hline Externalizing problems & $0.95(0.76,1.19)$ & & $1.02(0.81,1.27)$ \\
\hline Internalizing problems & $1.29(1.05,1.59)$ & & $1.26(1.05,1.51)$ \\
\hline Social-perception & $1.35(1.10,1.67)$ & & $1.39(1.15,1.69)$ \\
\hline
\end{tabular}

IRR Incidence rate ratio, 95\% CI 95\% confidence interval; Model 1: IRR's are mutually adjusted for all variables in the table and for energy intake but not for the self-esteem variables; Model 2: IRR's are mutually adjusted for all variables in the table, including the self-esteem variables, and for energy intake. Estimates are weighted to represent grade five students in Nova Scotia. Bold values for IRRs and $95 \%$ Cls indicate statistical significance $(p<0.05)$

study showing that screen time in children is related to psychological problems irrespective of physical activity [50].

The effects of socio-demographic characteristics of students on internalizing disorders are in line with those of previous studies [51-53]. Girls used more health care services for internalizing disorders (IRR $=1.61,95 \%$ CI: $1.33,1.96)$ than boys during the follow up period. Higher levels of household income were strongly associated with lower health care contacts with physicians for internalizing disorders (Table 3). The results highlight the importance of targeting mental health promotion programs towards girls and those children among socioeconomically disadvantaged communities and families.

Policies and programs promoting healthy eating and active living among children aim to reduce excess body weight and prevent the development of chronic diseases later in life. The findings of the present study suggest that such policies and programs may also reduce the burden of internalizing disorders in adolescence and in adulthood. Where programs promote healthy eating, active living and self-esteem simultaneously, the benefits for mental health are expectedly higher as the present study revealed the importance of self-esteem in childhood for internalizing disorders in adolescence independent of these health behaviours. Examples of such programs include comprehensive school health programs. Their benefits to physical health have been demonstrated [30, 54], but benefits for mental health have yet to be examined and reported.

Strengths of this study include the use of a large population-based sample linked with longitudinal administrative health data, the use of a prospective design, the consideration of a variety of potential confounders including coinciding health behaviours, socio-demographic factors and self-esteem, the use of health care provider diagnoses for internalizing disorders which provides an objective and clinically meaningful assessment of internalizing disorders, and lastly, the fact that we monitored the outcome of interest for a period of 8 years, which is longer than in the few other studies. The interpretation of the study findings needs to consider several limitations. Assessment of child physical activity and sedentary behaviours used self-report, and thus is prone to recall bias. Food intake was also based on self-reported food frequency, which may also be subject 
to error, although the Harvard YAQ measure has been validated in this population [55]. Objective measures of these behaviours in future studies would allow for more accurate assessment for the exposure-outcome relations. Finally, in assessing internalizing disorders, we only considered children who had contacts with health-care providers relating to this diagnosis. Children with internalizing disorders who did not seek health care services or had barriers in accessing health care during the follow-up period may have been missed. This may have resulted in an underestimation of both the numbers of children experiencing internalizing disorders and the number of health care visits.

\section{Conclusions}

We revealed in this study that variety in the diet, physical inactivity and sedentary behaviour in childhood are independently associated with the development of internalizing disorders in adolescence. These findings suggest that health promotion programs aiming to improve children's diets and physical activity behaviours may also contribute to the prevention of mental disorders, providing further evidence that health behaviours and mental health are linked.

\section{Additional file}

Additional file 1: Table S1. Logistic regressions for the associations of health behaviours in childhood with internalizing disorder in adolescence among participants of the Children's Lifestyle and School Performance Study, Nova Scotia, Canada. (DOCX 20 kb)

\section{Abbreviations}

CIHI: Canadian Institute for Health Information; CLASS: Children's Lifestyle and School Performance Study; DAD: Discharge Abstract Database; DQI-I: Diet quality index-international; ICD-10-CA: International Classification of Diseases, Tenth Revision, Canadian version; ICD-9-CM: International Classification of Diseases, Ninth Revision, Clinical Modification; MSI: Medical Services Insurance; NBM: Negative binomial regression models; PA: Physical activity

\section{Acknowledgements}

The authors would like to thank students, parents, and schools for their participation in the CLASS study. We thank Angela Fitzgerald for her role as project coordinator of the CLASS study, research assistants and public health staff members who assisted in the data collection, and Jason Liang and Connie Lu for data validation and management of the CLASS survey data. We thank Dr. Yen Chu and Sarah Loehr for their roles as project coordinators for this ROI4Kids CRIO project, and thank Dr. Leslie Anne Campbell, Craig Gorveatt, Sandra Pauls and Yan Wang from Health Data Nova Scotia for their support and assistance in accessing the administrative health data.

\section{Funding}

The CLASS study was funded through an operating grant by the Canadian Population Health Initiative to PJV. The present analysis was funded through the Collaborative Research and Innovation Opportunities (CRIO) Team program from Alberta Innovates-Health Solutions awarded to PJV and AO. XYW received a postdoctoral stipend through this CRIO program. PJV holds a Canada Research Chair in Population Health, an Alberta Research Chair in Nutrition and Disease Prevention, and an Alberta Innovates Health Scholarship. SFLK holds a Canada Research Chair in Health Services Research funded by CIHR. All interpretations and opinions in the present study are those of the authors.

\section{Availability of data and materials}

The administrative health data are not allowed to be taken out of HDNS Details of the data access process are available from: https://medicine.dal.ca/ departments/department-sites/community-health/research/hdns/data-accessguidelines.html.

\section{Research ethics}

The data collection and parental informed consent forms of the CLASS study were approved by the Human Research Ethics Boards of Dalhousie University and the University of Alberta. The data linkage of the CLASS survey data with the administrative health data was approved by Human Research Ethics Boards of the University of Alberta and Dalhousie University, and by Health Data Nova Scotia, the custodian of the administrative health data. All analyses, including the data linkage, were performed within a secure location through Health Data Nova Scotia (HDNS) and subject to vetting by HDNS analysts. The administrative health data are not allowed to be taken out of HDNS. Details of the data access process are available from: https:// medicine.dal.ca/departments/department-sites/community-health/research/ hdns/data-access-guidelines.html

\section{Authors' contributions}

PJV conceived the study, advised on the analyses and wrote the manuscript. XYW conducted the statistical analysis, literature review and drafted the manuscript. SFLK, AO advised on the analyses and wrote the manuscript. All authors read and approved the final manuscript.

\section{Ethics approval and consent to participate}

Written informed consent had been collected from the parents or legal guardians of all participants. The data collection and parental informed consent forms of the CLASS study were approved by the Human Research Ethics Boards of Dalhousie University and the University of Alberta. The data linkage of the CLASS survey data with the administrative health data was approved by Human Research Ethics Boards of the University of Alberta and Dalhousie University, and by Health Data Nova Scotia, the custodian of the administrative health data. All analyses, including the data linkage, were performed within a secure location through Health Data Nova Scotia (HDNS) and subject to vetting by HDNS analysts.

\section{Consent for publication}

Not applicable.

\section{Competing interests}

The authors have no competing interests.

\section{Publisher's Note}

Springer Nature remains neutral with regard to jurisdictional claims in published maps and institutional affiliations.

\section{Author details}

${ }^{1}$ Healthy Populations Institute, Dalhousie University, Halifax, NS, Canada. ${ }^{2}$ IWK Health Centre, Halifax, NS, Canada. ${ }^{3}$ School of Public Health, University of Alberta, Edmonton, AB T6G 1C9, Canada.

Received: 27 February 2017 Accepted: 27 November 2017

Published online: 12 December 2017

\section{References}

1. Kessler RC, Aguilar-Gaxiola S, Alonso J, Chatterji S, Lee S, Ormel J, et al. The global burden of mental disorders: an update from the WHO world mental health (WMH) surveys. Epidemiol Psichiatr Soc. 2009;18(1):23-33.

2. Patel V, Flisher AJ, Hetrick S, McGorry P. Mental health of young people: a global public-health challenge. Lancet. 2007;369(9569):1302-13.

3. Kessler RC, Amminger GP, Aguilar-Gaxiola S, Alonso J, Lee S, Ustün TB. Age of onset of mental disorders: a review of recent literature. Curr Opin Psychiatry. 2007;20(4):359-64.

4. Shaffer D, Gould MS, Fisher P, Trautman P, Moreau D, Kleinman M, et al. Psychiatric diagnosis in child and adolescent suicide. Arch Gen Psychiatry. 1996;53(4):339-48

5. McGee R, Williams S, Nada-Raja S. Low self-esteem and hopelessness in childhood and suicidal ideation in early adulthood. J Abnorm Child Psychol. 2001;29(4):281-91. 
6. O'Neil A, Quirk SE, Housden S, Brennan SL, Williams LJ, Pasco JA, et al. Relationship between diet and mental health in children and adolescents: a systematic review. Am J Public Health. 2014;104(10):e31-42.

7. Oddy WH, Robinson M, Ambrosini GL, O'Sullivan TA, de Klerk NH, Beilin L, et al. The association between dietary patterns and mental health in early adolescence. Prev Med. 2009;49(1):39-44.

8. Biddle SJ, Asare M. Physical activity and mental health in children and adolescents: a review of reviews. Br J Sports Med. 2011;45(11):886-95.

9. Cao H, Qian Q, Weng T, Yuan C, Sun Y, Wang H, et al. Screen time, physical activity and mental health among urban adolescents in China. Prev Med. 2011;53(4-5):316-20.

10. Kremer P, Elshaug C, Leslie E, Toumbourou JW, Patton GC, Williams J. Physical activity, leisure-time screen use and depression among children and young adolescents. J Sci Med Sport. 2014;17(2):183-7.

11. Allison KR, Adlaf EM, Irving HM, Hatch JL, Smith TF, Dwyer JJ, et al. Relationship of vigorous physical activity to psychologic distress among adolescents. J Adolesc Health. 2005:37(2):164-6.

12. Janssen I, Leblanc AG. Systematic review of the health benefits of physical activity and fitness in school-aged children and youth. Int J Behav Nutr Phys Act. 2010;7:40

13. Suchert V, Hanewinkel $R$, Isensee B. Sedentary behavior and indicators of mental health in school-aged children and adolescents: a systematic review. Prev Med. 2015;76:48-57.

14. Tremblay MS, LeBlanc AG, Kho ME, Saunders TJ, Larouche R, Colley RC, et al. Systematic review of sedentary behaviour and health indicators in schoolaged children and youth. Int J Behav Nutr Phys Act. 2011;8:98

15. Maras D, Flament MF, Murray M, Buchholz A, Henderson KA, Obeid N, et al. Screen time is associated with depression and anxiety in Canadian youth. Prev Med. 2015;73:133-8.

16. Herman KM, Hopman WM, Sabiston CM. Physical activity, screen time and self-rated health and mental health in Canadian adolescents. Prev Med. 2015;73:112-6.

17. Jacka FN, Kremer PJ, Berk M, de Silva-Sanigorski AM, Moodie M, Leslie ER, et al. A prospective study of diet quality and mental health in adolescents. PLoS One. 2011;6(9):e24805.

18. Jacka FN, Rothon C, Taylor S, Berk M, Stansfeld SA. Diet quality and mental health problems in adolescents from East London: a prospective study. Soc Psychiatry Psychiatr Epidemiol. 2013:48(8):1297-306.

19. McMartin SE, Kuhle S, Colman I, Kirk SF, Veugelers PJ. Diet quality and mental health in subsequent years among Canadian youth. Public Health Nutr. 2012;15(12):2253-8

20. Hoegh Poulsen $\mathrm{P}$, Biering $\mathrm{K}$, Andersen $\mathrm{JH}$. The association between leisure time physical activity in adolescence and poor mental health in early adulthood: a prospective cohort study. BMC Public Health. 2016;16:3.

21. Sagatun A, Søgaard AJ, Bjertness E, Selmer R, Heyerdahl S. The association between weekly hours of physical activity and mental health: a three-year follow-up study of 15-16-year-old students in the city of Oslo, Norway. BMC Public Health. 2007;7:155.

22. Wiles NJ, Jones GT, Haase AM, Lawlor DA, Macfarlane GJ, Lewis G. Physical activity and emotional problems amongst adolescents: a longitudinal study. Soc Psychiatry Psychiatr Epidemiol. 2008;43(10):765-72.

23. McKercher C, Sanderson K, Schmidt MD, Otahal P, Patton GC, Dwyer T, et al. Physical activity patterns and risk of depression in young adulthood: a 20-year cohort study since childhood. Soc Psychiatry Psychiatr Epidemiol. 2014;49(11): 1823-34.

24. Rothon C, Edwards P, Bhui K, Viner RM, Taylor S, Stansfeld SA. Physical activity and depressive symptoms in adolescents: a prospective study. BMC Med. 2010;8:32.

25. Toseeb U, Brage S, Corder K, Dunn VJ, Jones PB, Owens M, et al. Exercise and depressive symptoms in adolescents: a longitudinal cohort study. JAMA Pediatr. 2014;168(12):1093-100.

26. Hume C, Timperio A, Veitch J, Salmon J, Crawford D, Ball K. Physical activity, sedentary behavior, and depressive symptoms among adolescents. J Phys Act Health. 2011;8(2):152-6.

27. Boden JM, Fergusson DM, Horwood LJ. Does adolescent self-esteem predict later life outcomes? A test of the causal role of self-esteem. Dev Psychopathol. 2008:20(1):319-39.

28. Kisely S, Lin E, Gilbert C, Smith M, Campbell LA, Vasiliadis HM. Use of administrative data for the surveillance of mood and anxiety disorders. Aust N Z J Psychiatry. 2009;43(12):1118-25.
29. Fiest KM, Jette N, Quan H, St Germaine-Smith C, Metcalfe A, Patten SB, et al. Systematic review and assessment of validated case definitions for depression in administrative data. BMC Psychiatry. 2014;14:289.

30. Veugelers PJ, Fitzgerald AL. Effectiveness of school programs in the prevention of childhood obesity. Am J Public Health. 2005;95:432-5.

31. Rockett HR, Wolf AM, Colditz GA. Development and reproducibility of a food frequency questionnaire to assess diets of older children and adolescents. J Am Diet Assoc. 1995;95:336-40.

32. Health Canada Food and Nutrition: The Canadian Nutrient File. 2007. https://www.canada.ca/en/health-canada/services/food-nutrition/healthyeating/nutrient-data.html. Accessed 13 Jan 2017

33. Kim S, Haines PS, Siega-Riz AM, Popkin BM. The diet quality indexinternational (DQI-I) provides an effective tool for cross-national comparison of diet quality as illustrated by China and the United States. J Nutr. 2003; 133(11):3476-84.

34. Statistics Canada (2003). National longitudinal survey of children and youth (NLSCY). 2003.http://www23.statcan.gc.ca/imdb-bmdi/instrument/4450_Q2 V3-eng.pdf. Accessed 13 Jan 2017.

35. Cole TJ, Bellizzi MC, Flegal KM, Dietz WH. Establishing a standard definition for child overweight and obesity worldwide: international survey. BMJ. 2000; 320(7244):1240-3.

36. Willett WC, Howe GR, Kushi LH. Adjustment for total energy intake in epidemiologic studies. Am J Clin Nutr. 1997;65(4 Suppl):S1220-8.

37. Wang F, Veugelers PJ. Self-esteem and cognitive development in the era of the childhood obesity epidemic. Obes Rev. 2008;9(6):615-23.

38. Wu XY, Kirk SF, Ohinmaa A, Veugelers PJ. Health behaviours, body weight and self-esteem among grade five students in Canada. SpringerPlus. 2016;5:1099.

39. Cameron AC, Trivedi PK. Regression analysis of count data, 2nd edition, econometric society monograph no.53, Cambridge University Press, Cambridge, May 2013.

40. Veugelers PJ, Fitzgerald AL. Prevalence of and risk factors for childhood overweight and obesity. CMAJ. 2005:173:607-13.

41. Foote JA, Murphy SP, Wilkens LR, Basiotis PP, Carlson A. Dietary variety increases the probability of nutrient adequacy among adults. J Nutr. 2004; 134(7):1779-85.

42. Ströhle A, Höfler M, Pfister H, Müller AG, Hoyer J, Wittchen HU, et al. Physical activity and prevalence and incidence of mental disorders in adolescents and young adults. Psychol Med. 2007;37(11):1657-66.

43. Motl RW, Birnbaum AS, Kubik MY, Dishman RK. Naturally occurring changes in physical activity are inversely related to depressive symptoms during early adolescence. Psychosom Med. 2004;66(3):336-42.

44. Van Dijk ML, Savelberg HH, Verboon P, Kirschner PA, De Groot RH. Decline in physical activity during adolescence is not associated with changes in mental health. BMC Public Health. 2016;16(1):300.

45. Mathers M, Canterford L, Olds T, Hesketh K, Ridley K, Wake M. Electronic media use and adolescent health and well-being: cross-sectional community study. Acad Pediatr. 2009;9(5):307-14.

46. Sund A, Larsson B, Wichstrøm L. Role of physical and sedentary activities in the development of depressive symptoms in early adolescence. Soc Psych Psych Epid. 2011:46:431-41.

47. Özmert E, Toyran M, Yurdakok K. Behavioral correlates of television viewing in primary school children evaluated by the child behavior checklist. Arch Pediatr Adolesc Med. 2002;156(9):910-4.

48. Primack BA, Swanier B, Georgiopoulos AM, Land SR, Fine MJ. Association between media use in adolescence and depression in young adulthood: a longitudinal study. Arch Gen Psychiatry. 2009;66(2):181-8.

49. Grøntved A, Singhammer J, Froberg K, Møller NC, Pan A, Pfeiffer KA, et al. A prospective study of screen time in adolescence and depression symptoms in young adulthood. Prev Med. 2015;81:108-13.

50. Page AS, Cooper AR, Griew P, Jago R. Children's screen viewing is related to psychological difficulties irrespective of physical activity. Pediatrics. 2010; 126(5):e1011-7.

51. Reiss F. Socioeconomic inequalities and mental health problems in children and adolescents: a systematic review. Soc Sci Med. 2013:90:24-31.

52. Dray J, Bowman J, Freund M, Campbell E, Hodder RK, Lecathelinais C, et al. Mental health problems in a regional population of Australian adolescents: association with socio-demographic characteristics. Child Adolesc Psychiatry Ment Health. 2016:10(1):32

53. Allison SL, Roeger G, Martin J. Gender differences in the relationship between depression and suicidal ideation in young adolescents. Aust N Z J Psychiatry. 2001;34:498-503. 
54. Fung C, Kuhle S, Lu C, Purcell M, Schwartz M, Storey K, et al. From "best practice" to "next practice": the effectiveness of school-based health promotion in improving healthy eating and physical activity and preventing childhood obesity. Int J Behav Nutr Phys Act. 2012;9:27.

55. Rockett HR, Breitenbach M, Frazier AL, Witschi J, Wolf AM, Field AE, et al. Validation of a youth/adolescent food frequency questionnaire. Prev Med. 1997;26(6):808-16.

Submit your next manuscript to BioMed Central and we will help you at every step:

- We accept pre-submission inquiries

- Our selector tool helps you to find the most relevant journal

- We provide round the clock customer support

- Convenient online submission

- Thorough peer review

- Inclusion in PubMed and all major indexing services

- Maximum visibility for your research

Submit your manuscript at www.biomedcentral.com/submit 